\title{
ASPECTOS DA ARQUITETURA DA INFORMAÇÃO ENVOLVIDOS NO MAPEAMENTO DE PROCESSOS EM ORGANIZAÇÕES MILITARES SOB A PERSPECTIVA SEMIÓTICA
}

\author{
ASPECTOS DE ARQUITECTURA DE LA \\ INFORMACIÓN QUE PARTICIPAN EN EL MAPEO \\ DE PROCESOS EN LAS ORGANIZACIONES \\ MILITARES EN LA PERSPECTIVA SEMIÓTICA
}

\author{
Mac Amaral Cartaxo* \\ Cláudio Gottschalg Duque**
}

\begin{abstract}
RESUMO
Introdução: A descrição dos processos visando representar as atividades desenvolvidas numa organização possui importante apelo semiótico, seja pelos usos de fluxogramas, relatórios de gestão e das diversas formas de representação das estratégias utilizadas. A posterior interpretação dos colaboradores da organização envolvidos na aprendizagem das tarefas e os símbolos utilizados para traduzir os significados das práticas de gestão tem papel imprescindível para a organização.

Objetivo: O objetivo deste estudo foi identificar indícios da natureza conceitual e empírica, sobre os aspectos da arquitetura da informação envolvidos no mapeamento de processos realizado em organizações militares sob a perspectiva semiótica.

Metodologia: A pesquisa caracteriza-se como qualitativa, estudo de caso e a de técnica de coleta de dados foi a entrevista semiestruturada, aplicada aos assessores de gestão.

Resultados: Os principais resultados indicam que as práticas de gestão descritas com a utilização de símbolos pictóricos e layouts diferenciados possuem maior impacto para explicitar a relevância das práticas de gestão e seus indicadores.

Conclusão: No que diz respeito ao apelo semiótico, verificou-se que o impacto de um relatório de gestão é expressivo devido ao uso de signos e layout que estimulam a prosseguir a leitura pela simplificação de conceitos complexos em tabelas, diagramas que resumam longas descrições.
\end{abstract}

*Doutorando em Ciência da Informação pela Universidade de Brasília (UnB). Docente no Centro Universitário do Distrito Federal (UDF). E-mail: maccartaxo@gmail.com

**Doutor em Linguística Aplicada e Linguística Computacional pela Justus Liebig Universität Giessen, Alemanha. Professor na Universidade de Brasília (UnB). E-mail: klaussherzog@gmail.com

Inf. Inf., Londrina, v. 21, n. 1, p. $103-130$, jan./abr. 2016.

http:www.uel.br/revistas/informacao/ 
Palavras-chave: Arquitetura da Informação. Mapeamento de Processos. Excelência Gerencial. Organizações Militares. Semiótica.

\section{INTRODUÇÃO}

Desenvolver um projeto de análise, descrição e melhoria de processos é uma empreitada que envolve complexidade e dificuldade no que tange a capacidade de representar os diversos aspectos envolvidos. Através dele, o analista deverá transmitir uma realidade viva, dinâmica e rica para uma perspectiva estática e silenciosa. Naturalmente, questões relacionadas a seleção e a codificação das informações deverão ser minuciosamente trabalhadas pelo analista, face aos objetivos pretendidos e, também, às características do usuário que decodificará posteriormente o fluxograma.

Nos diversos modelos de mapeamento de processos, que adotam a informação como elemento considerado insumo necessário aos processos de construção do significado e de representação das atividades e atores envolvidos no processo, as dimensões interpretação, como por exemplo, o de distribuição da informação propostas por Huber (1991) estão incorporadas,

O que se busca analisar é como as lacunas existentes no uso da informação, interferem no processo de descrição de um processo que deve ser mapeado de modo a ser reconhecido no nível individual, e passível de melhoria a partir de uma análise no nível organizacional.

Neste sentido a arquitetura da informação conforme Toub é a arte e a ciência de estruturar e organizar ambientes de informação para ajudar as pessoas a satisfazerem suas necessidades de informação de forma efetiva. (TOUB, 2000). Macedo de forma mais pragmática caracteriza a arquitetura da informação como responsável por resolver os problemas da busca, organização e apresentação da informação em analogia aos problemas da arquitetura de construções que irão servir às necessidades de seus moradores (MACEDO, 2005). 
Várias abordagens de gestão foram desenvolvidas e implementadas nos últimos anos visando organizar a informação e o conhecimento de modo a possibilitar a melhor descrição dos processos organizacionais, como é o caso da organização, sistemas e métodos, reengenharia, gestão da qualidade total e própria BPM (Bussiness Process Management).

O ponto em comum entre estas abordagens é a utilização de símbolos para descrever e representar os processos de negócio que se busca conhecer e melhorar. Deste modo, a semiótica se mostra pertinente para analisar a utilização de modelos de gestão que contemplem práticas de gestão passíveis de serem representadas por intermédio de símbolos, pois a semiótica de que se trata aqui, define-se também como estudo de lógica. É a ciência dos signos que investiga e busca o entendimento de toda e qualquer linguagem (verbal ou nãoverbal). A semiótica "é uma ciência formal e abstrata, num nível de generalidade ímpar" (SANTAELLA, 2003, p.43).

Nessa perspectiva, o estudo visa apresentar os aspectos da Arquitetura da Informação envolvidos no mapeamento de processos sob a perspectiva semiótica. Para isto, serão apresentadas, as definições e onde está inserida a Arquitetura da Informação, as definições de semiótica. Por fim, conclui o trabalho apresentando os aspectos identificados no mapeamento de processos realizado em organizações militares e as perspectivas da semiótica contempladas na descrição.

$\mathrm{Na}$ área da gestão o texto se mostra como um dos meios mais comuns de apresentação da informação. Sabe-se que um texto, na ciência da informação, é uma coleção de signos propositadamente estruturados por um emissor com a intenção de mudar a estrutura da imagem de um receptor.

Neste sentido é sabido que para analisar o contexto social ou política de um texto, se faz necessário levar em consideração, de um lado, as representações ideológicas dos atores e, de outro, a informação que é gerada dentro da situação observada, codificados pela linguagem. 
A aplicação dos conceitos de gerenciamento de processos nas organizações tem sido um dos pontos centrais dos modelos de gestão da qualidade ou de excelência gerencial. Para que o mapeamento, analise e melhoria de processos ocorra se faz necessária a utilização a codificação dos processos e procedimentos operacionais da organização.

É na semiótica que se pode obter ferramental para investigar as codificações da linguagem, pois a semiótica é a ciência dos signos, sendo reconhecida como a ciência de toda e qualquer linguagem (SANTAELLA, 2003), ou seja, visa o exame dos modos de constituição de todo e qualquer fenômeno de produção de significação e de sentido (SANTAELLA, 2005). Indo além da linguística, pois não se limita ao estudo do sistema sígnico da linguagem verbal, indo além, na medida em que ter por interesse qualquer sistema sígnico incluindo artes visuais, fotografia, cinema, música, culinária, vestuário, gestos, religião, ciência, e tantos outros. Deste modo os símbolos necessários para a descrição de um processo organizacional, por intermédio, de um fluxograma se encontra contemplado.

Logo, baseado no contexto acima apresentado, a questão da pesquisa consiste em levantar quais são os aspectos da arquitetura da informação que estão envolvidos no mapeamento de processos sob uma perspectiva semiótica?

É deste modo, objetivo geral deste artigo, analisar os aspectos da Arquitetura da Informação envolvidos no mapeamento de processos sob uma perspectiva semiótica.

Os objetivos específicos delimitados para propiciar o atingimento do objetivo geral proposto foram: a. Definir a Arquitetura da Informação levando em consideração perspectivas de pesquisadores renomados, assim como, os diversos contextos aos quais a mesma se insere; $b$. Contextualizar a abordagem semiótica; $d$. Caracterizar o mapeamento de processos desenvolvido nas organizações militares que adotam o Modelo de Excelência Gerencial do Exército Brasileiro; e. Identificar 
aspectos que circunscrevem a Al em relação a abordagem semiótica num contexto de análise e melhoria de processos.

Para atingir os objetivos propostos e responder o problema de pesquisa proposto, o artigo está organizado da forma como se segue: $\mathrm{Na}$ seção 2 serão descritos os procedimentos metodológicos utilizados na pesquisa; A seção 3 apresenta uma revisão da literatura, na qual são abordadas definições, modelos e onde se insere a $\mathrm{Al}$, Na seção 4 são descritos a perspectiva do Modelo de Excelência Gerencial e processos organizacionais; A seção 5 expõe conceitos sobre semiótica ; $\mathrm{Na}$ seção 6 serão descritos os relacionamentos entre a semiótica e o mapeamento de processos do Modelo de Excelência Gerencial do Exército Brasileiro identificados na pesquisa e contidos no Sistema de Excelência Gerencial do Exército Brasileiro - versão WEB ; Por fim, a seção 7 conclui este trabalho apresentando as considerações finais desta pesquisa.

\section{PROCEDIMENTOS METODOLÓGICOS}

Os procedimentos adotados na pesquisa referem-se à maneira pela qual o estudo foi conduzido, portanto, para a coleta e análise de dados foram utilizadas as leituras seletiva e interpretativa com o intuito de construir o referencial teórico necessário a fundamentação da pesquisa bibliográfica.

$\mathrm{Na}$ visão de Cervo e Bervian (1983) a pesquisa bibliográfica explica um problema a partir de referenciais teóricos publicados em documentos. Assim sua finalidade consiste em conhecer e analisar as contribuições científicas existentes sobre determinado assunto, tema ou problema.

A pesquisa tem caráter exploratório, ou seja, destina-se a obter nova percepção do fenômeno e descobrir novas ideias. Assim, foram realizados levantamentos e descrições sobre a semiótica em relação ao 
mapeamento de processos com o propósito de descobrir as relações existentes entre os elementos componentes destes dois construtos.

Nessa perspectiva, através da localização, seleção e consulta de fontes bibliográficas centradas na arquitetura da informação, semiótica e mapeamento de processos foi possível coletar dados específicos a respeito dos temas. O levantamento seletivo dessas informações permitiu uma avaliação crítica, rejeitando informações claramente inadequadas, mal produzidas ou redundantes.

A presente pesquisa também se caracteriza como um estudo de natureza descritiva, na medida, em que, segundo Gil $(2002,42)$ " as pesquisas descritivas têm como objetivo primordial a descrição das características de determinada população ou fenômeno ou, então, o estabelecimento de relações entre variáveis." O objeto da pesquisa foi a arquitetura da informação adotada no mapeamento e documentação de processos das práticas de gestão contida no Sistema de Excelência Gerencial do Exército Brasileiro - versão WEB numa perspectiva semiótica. A organização foi escolhida em função da conveniência e também em virtude de se tratar de uma organização reconhecida e premiada pela Fundação Nacional da Qualidade (FNQ) e pelo Programa Nacional de Gestão Pública e Desburocratização (GESPÚBLICA) como possuidora de práticas de gestão alinhadas e documentadas vinculadas aos critérios de excelência gerencial.

Nesta pesquisa, o estudo de caso foi desenvolvido, por intermédio, de pesquisa documental feita no próprio Sistema de Excelência Gerencial do Exército Brasileiro - versão WEB sobre como as organizações militares descrevem as suas práticas de gestão, tendo sido escolhido pelo menos um processo finalístico de cada organização, além, de entrevistas com os 7 assessores de gestão responsáveis em cada um dos órgãos de direção setorial, os 6 assessores de gestão dos órgãos de assessoramento direto e imediato, além de 3 militares do órgão de direção geral responsáveis pelo gerenciamento do sistema. Também foi feita coleta da documentação sobre a ferramenta do 
Sistema de Excelência Gerencial do Exército Brasileiro - versão WEB. Importante destacar que todos os participantes da pesquisa possuem nível superior, idade entre 28 e 65 anos, 7 anos ou mais de serviço, porém nem todos com experiência significativa no modelo de excelência e na modelagem de processos.

A pesquisa documental dos processos de negócio consistiu no levantamento das descrições das práticas de gestão, a partir dos Critérios de Excelência descritos no modelo de excelência gerencial. Foram abordados aspectos sobre: o que é feito, a pertinência da prática para atender aos requisitos esperados, o nível de disseminação e clareza para toda a organização do procedimento a ser desenvolvido, quem é o responsável, os principais atores envolvidos, qual o papel desempenhado por cada um deles, desde quando é realizada a prática de gestão, qual o inter-relacionamento com outros processos, os produtos gerados, e os principais indicadores que demonstram a tendência favorável ou não do processo.

Os procedimentos de análise dos dados adotados foram (YIN, 2005): (a) análise de conteúdo das gravações e anotações pelos pesquisadores individualmente após cada entrevista; (b) análise da percepção sobre o que foi descrito no Sistema de Excelência Gerencial do Exército Brasileiro - versão WEB sobre o processo objeto de estudo de cada Órgão de Direção Setorial respectivamente em relação ao que foi respondido pelo respectivo assessor de gestão; (c) validação dos resultados preliminares das análises com os participantes; (d) análise geral das anotações da consulta à documentação disponibilizada buscando identificar a coerência entre o que foi respondido, o que se encontra descrito sobre as práticas gerenciais em relação aos indicadores dos processos, de modo a demonstrar a coerência e clareza da descrição das práticas de gestão, por intermédio de fluxogramas, tabelas ou relatos organizacionais e os resultados registrados nos indicadores dos processos; (e) por fim, análise das informações obtidas relacionando-as com o proposto na literatura sobre o tema. 


\section{ARQUITETURA DA INFORMAÇÃO}

Foi possível identificar inúmeras definições sobre o que é ou o que constitui uma Arquitetura da Informação. Observa-se, dentre os vários pesquisadores que escrevem sobre o assunto, uma grande quantidade e diversidade de definições do termo.

Dessa forma, é importante apontar que o termo "Arquitetura da Informação" (Al) foi empregado originalmente pelo arquiteto Richard Saul Wurman em 1976, que a define como "ciência e a arte de criar instruções para espaços organizados". Na visão de Macedo (2005) os problemas da busca, organização e apresentação da informação são identificados como análogos aos problemas da arquitetura de construções que irão servir às necessidades de seus moradores.

Conforme o anteriormente exposto, o trabalho tem a finalidade de apresentar os aspectos interdisciplinares entre o campo de pesquisa da Arquitetura da Informação e a abordagem multimodal para a Aprendizagem Organizacional em um Modelo de Excelência Gerencial (MEG).

Adota-se, aqui, a definição de Lima-Marques como ponto de partida para as discussões em torno do tema: "Al - É o escutar, o construir, o habitar e o pensar a informação como atividade de fundamento e de ligação hermenêutica de espaços, desenhados ontologicamente para desenhar" (LIMA-MARQUES, 2011,p. 13 ).

Sob o ponto de vista organizacional, há que se destacar também a definição de Brancheau e Wetherbe, os quais afirmam que Arquitetura da Informação consiste em um plano para modelagem dos requisitos informacionais de uma organização. Esse plano provê um modo de mapear as informações necessárias à organização, relativas aos processos do negócio e documentar seus Inter relacionamentos (BRANCHEAU e WETHERBE, 1986). 
No entanto, apresentam-se a seguir outras definições de Al presentes na literatura, cujos enfoques vão da esfera organizacional a ambientes informacionais diversos.

Na visão de Davenport (1998), a Al simplesmente constitui-se de uma série de ferramentas que adaptam os recursos às necessidades da informação. Um projeto bem implementado estrutura os dados em formatos, categorias e relações específicas. A arquitetura faz a ponte entre o comportamento, os processos e o pessoal especializado e outros aspectos da empresa, como métodos administrativos, estrutura organizacional e espaço físico.

Porém na perspectiva de Rosenfeld e Morville (2002), a Al consiste na combinação da organização, dicionarização e esquemas de navegação em sistemas de informação.

Entretanto, Bailey (2003, p.7) afirma que a Al é a "arte e a ciência de organizar os sistemas de informação para auxiliar o usuário a alcançar seus objetivos”. Os arquitetos da informação organizam o conteúdo e projetam sistemas de navegação para auxiliar os usuários a encontrar e gerenciar informação.

Nas definições de Al apresentadas anteriormente, nota-se que existe uma unanimidade em afirmar que o seu foco principal é o tratamento da informação na sua totalidade, sem se prender à nenhuma técnica específica de modelagem de dados ou arquitetura de sistemas de informação.

Seguindo esse enfoque, Rosenfeld e Morville (2002) propõem o modelo ilustrado na figura 1, para representar a Arquitetura da Informação. A Al é representada como a interseção de contexto, conteúdo e usuários. Para que o espaço informacional de uma organização seja bem projetado, há necessidade de se conhecer os objetivos do negócio da organização (contexto), estar consciente da natureza e volume de informações existentes e sua taxa de crescimento (conteúdo) e de se entender as necessidades e os processos de busca do público-alvo (usuários). 
Figura 1 - Modelo de Arquitetura da Informação.

Objetivos do Negócio

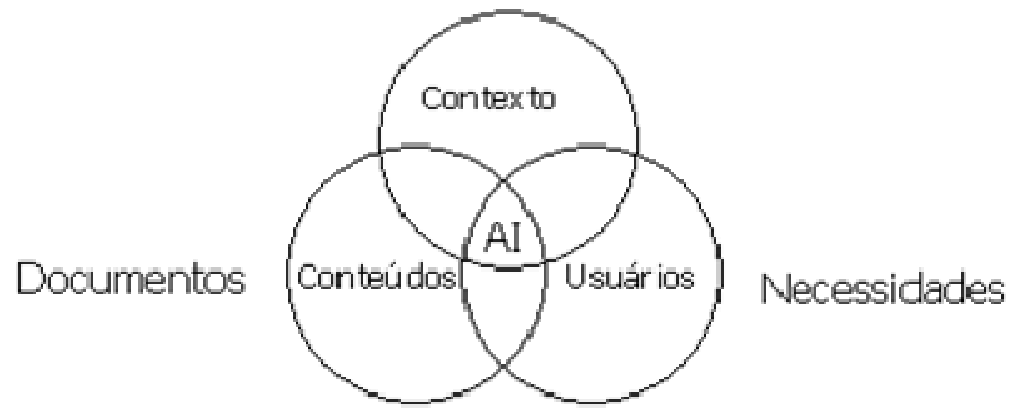

Fonte: (Rosenfeld e Morville, 2002)

Também é possível encontrar definições de Arquitetura da Informação - (BELTON, 2003), (WODTKE, 2002), (GARRETT, 2004) fortemente relacionadas à apresentação da informação em sítios na Web, confundindo o conceito de Al com o conceito de Usabilidade (NIELSEN e TAHIR, 2002). Na verdade, usabilidade é apenas uma das disciplinas a serem abordadas em um projeto de Al.

Cabe ressaltar que a tecnologia desempenha um papel importante em uma $\mathrm{Al}$, mas o objetivo de uma $\mathrm{Al}$ é organizar e armazenar a informação estruturada, semiestruturada e não estruturada em repositórios informacionais (bancos de dados, sistemas de arquivos, etc) providos de consistência, compartilhamento, documentação, privacidade e recuperação eficaz de seus conteúdos.

Logo, pode-se inferir que em um ambiente com Al planejado, o enfoque deve ser a recuperação da informação, a descrição e semântica das estruturas de armazenamento dessas informações ou dados. Além dos usuários convencionais, os técnicos das áreas relacionadas ao tratamento da informação também deverão ser usuários dessa arquitetura. Assim, uma Al proporciona, além da recuperação da informação, o entendimento, compartilhamento e reusabilidade dos esquemas de representação e das estruturas de armazenamento das informações e dos dados. 


\section{MODELO DE EXCELÊNCIA GERENCIAL E PROCESSOS ORGANIZACIONAIS}

O tema excelência gerencial avultou em interesse nos últimos anos, recebendo diversas nomenclaturas e dimensões de análise. No início visto como qualidade total ou melhoria contínua e atualmente visto como um construto abrangente e funciona como um "guarda-chuva" que circunscreve vários campos de pesquisa e análise.

O estudo sobre a excelência e a gestão da qualidade tem seu marco relacionado às atividades de alguns pioneiros, conhecidos como os fundadores do campo de estudo. Encontram-se neste grupo Juran (1964), Feigenbaum (1956), Crosby (1979) e Deming (1986) cuja obra foi a de maior influência no estabelecimento e evolução do movimento da qualidade.

O conceito de reação em cadeia de Deming (1986), apresentado originalmente no Japão em 1950, advoga, contra o senso comum na época, que a melhoria da qualidade traria impactos diretos para o aumento da produtividade e dos níveis de lucratividade da empresa. Sua visão aponta principalmente para a melhoria da qualidade de produtos $\mathrm{e}$ serviços pela redução das incertezas e variações envolvidas no projeto e nos processos de realização. Trata-se do primeiro "modelo" envolvendo a qualidade.

A disseminação de modelos de gestão da qualidade tomou força a partir do surgimento dos prêmios nacionais de qualidade. De forma a estruturar todos os conceitos defendidos pelos pioneiros dentro de um modelo que pudesse ser compreendido, desdobrado e implementado pelas organizações americanas, visando a melhoria da qualidade e da produtividade, um grupo de especialistas sob a coordenação do NIST (National Institute of Standards and Technology) e da então ASQC (American Society for Quality Control, atual ASQ - American Society for Quality) analisou uma série de empresas bem sucedidas na adoção dos conceitos dos pensadores pioneiros, que eram então consideradas nos Estados Unidos "ilhas de excelência" pelo grau de sucesso que 
obtiveram durante a década de 1980 na competição contra as empresas japonesas, que estavam no auge de sua influência. Esse estudo buscava características comuns que diferenciassem essas empresas das demais, resultando na identificação de valores organizacionais facilmente percebidos como parte da cultura dessas empresas, sendo praticados por seus líderes e profissionais em todos os níveis. Esses valores foram considerados Fundamentos para formar uma cultura de gestão voltada para resultados. Estes valores são desdobrados posteriormente em Critérios e Requisitos que poderiam ser utilizados por outras organizações para evoluírem sua gestão e seu desempenho em nível de excelência (Baldrige National Quality Program, 2006).

Essa estrutura sistêmica formada por Requisitos, Critérios e Fundamentos serviu de base para o estabelecimento do Malcolm Baldrige National Quality Award, nos Estados Unidos em 1987 e do Modelo de Excelência da European Foundation for Quality Management (2003). No Brasil, o Modelo do Prêmio Nacional da Qualidade (PNQ) foi desenvolvido em 1991 tendo como referência o modelo americano (FUNDAÇÃO NACIONAL DA QUALIDADE, 2013). A partir daí, evoluiu por meio de um processo sistêmico de atualizações, conduzido pela Fundação Nacional da Qualidade (FNQ) para acompanhar a dinâmica da gestão empresarial e refletir características culturais do Brasil.

Mais recentemente, porém, a visão crítica sobre a gestão da qualidade vem crescendo no meio acadêmico. Materializando está crítica Benner e. Tushman (2003), questionam fortemente a aplicação dos conceitos de gerenciamento de processos nas organizações, ponto central dos modelos de gestão da qualidade. O foco dos pesquisadores recai sobre o efeito da gestão da qualidade na capacidade das empresas em gerar inovações, usando para isso os conceitos de exploration e exploitation introduzidos por March (1991). Benner e Tushman desenvolveram um conjunto de proposições que em sua síntese propõe que modelos de gestão baseados no gerenciamento de processos favorecem apenas as inovações incrementais, alinhadas ao 
desenvolvimento (exploitation) de competências e posições já existentes, buscando-se refinamento e eficiência, em prejuízo das inovações radicais, alinhadas à descoberta de novas competências (exploration) em ambientes abertos ao risco e à experimentação.

Neste contexto as informações consolidadas nas respostas aos requisitos e critérios propostos no Modelo de Excelências Gerencial são peças-chave para se obter conhecimentos necessários para fundamentar a criação das inovações esperadas, sendo estas respostas aos requisitos e critérios descritos em termos de processos que são representados em fluxos, tabelas e relatos organizacionais.

Tradicionalmente, um processo é definido como um conjunto de atividades inter-relacionadas ou interativas que transformam insumos (entradas) em produtos (saídas), para atender a um determinado cliente ou usuário. Os processos demandam atividades executadas por diversos atores dispostos em diferentes áreas ou setores e, para visando os resultados esperados, as organizações necessitam compreender o funcionamento destes processos, buscando aperfeiçoálos continuamente (RUMMLER e BRACHE, 1994; HAMMER e STANTON, 1999).

A obtenção de processos sistematizados implica a padronização tanto do fluxo de atividades como da forma de transferência de conhecimentos. É por intermédio, da constante reavaliação da estrutura organizacional, dos procedimentos operacionais padrão inseridos nos processos, bem como dos mecanismos de controle utilizados para aferir o desenvolvimento dos processos e resultados obtidos que a organização se torna capaz de fazer uma crítica pertinente sobre o seu desempenho e deste modo conseguir uma melhoria continua. Essa perspectiva caracteriza a demanda por decisões, diretrizes e ações capazes de influenciar o envolvimento das pessoas em nível estratégico, tático e organizacional de modo a propiciar o funcionamento harmônico dos processos em relação as estratégias de negócio da organização. 


\section{SEMIÓTICA}

Pode-se perceber que as organizações estão, cada vez mais, utilizando, diversos modos semióticos, que são usados e articulados ao mesmo tempo no processo de elaboração, conferindo-Ihes significados específicos. Neste sentido um dos construtos significativos é o da semiótica, e mais especificamente a semiótica peirciana.

Eco (1980), adota o termo semiótica como similar a semiologia, embora reconheça que as origens históricas distintas, pois enquanto o termo semiologia surge da linha "lingüístico-saussureana", o termo semiótica deriva da linha "filosófico-peirciana". Para Eco tanto Saussure como Peirce são pioneiros da semiótica contemporânea. Deste modo Eco (op cit) descreve as duas definições clássicas destes autores: "A língua é um sistema de signos que exprimem ideias, por isso, é confrontável com a escrita, o alfabeto dos surdos-mudos, os ritos simbólicos, as fórmulas de cortesia, os sinais militares..." (Saussure apud Eco, 1980, p. 9). Sendo considerado por este autor, o mais importante de tais sistemas.

Já Peirce (apud ECO, 1980), propõe s semiótica como a doutrina da natureza essencial das variedades fundamentais de cada semiose possível. Por sua vez o autor entende semiose com uma ação, uma influência, uma cooperação de três sujeitos: um signo, o seu objeto e o seu interpretante, não sendo possível a resolução em uma ação entre duplas.

Neste estudo, será adotado o viés proposto por Santaella (2005) e Bacha e Strehlau (2005), ou seja, a base teórica escolhida é a semiótica peirciana, na qual o artigo vai se pautar.

Os princípios gerais da semiótica peirciana consideram o homem como um ser simbólico e apto a carregar um signo de sentido (por exemplo, o gesto com a mão onde o indicador e o polegar juntos significa concordância, OK para algumas culturas, todavia o mesmo gesto com a mão em outras culturas significa um gesto obsceno); os 
símbolos expressam a cultura; a medida que as interações entre os indivíduos aumentam ou se diversificam, os signos crescem, se alteram em sua possibilidade de interpretação, bem como se tornam mais complexos. Já se tornou clássica a representação proposta por Peirce, denominada tríade semiótica que representa a teoria triádica do signo.

Figura 2 - Tríade semiótica

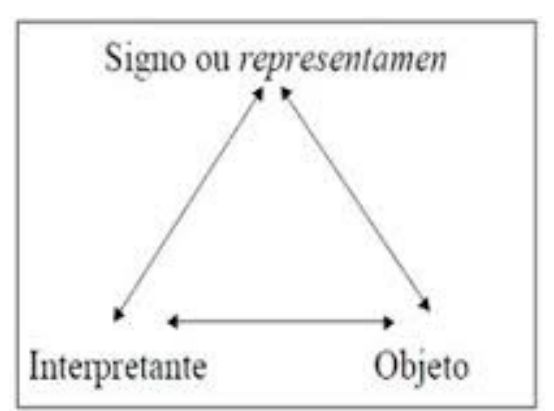

Fonte: Adaptado de Santaella, 2005

Segundo o pensamento triádico, o signo consegue capturar nele próprio o objeto e o sentido que ele gera. Ou seja, o signo é entendido como algo que representa alguma coisa (objeto) que ali não se encontra; signo é, portanto, um representâmen. O Interpretante é quem consegue a luz do signo atribuir um significado que pode representar objeto desejado.

Nesta esteira, Peirce formulou, ainda outras tríades dos signos (Santaella, 2004):

a) O signo em si mesmo: quali-signo, sin-signo e legi-signo.( quali-signo é a qualidade intrínseca do signo, por exemplo: as cores, as formas e a textura, dentre outros; sinsigno é o que há de singular ou único na mensagem, ou seja, a mensagem inserida em seu contexto; legi-signo é

uma convenção, por exemplo: as palavras de um idioma ou os sinais de trânsito)

b) A relação do signo com o objeto, seu referente (ícone, índice e símbolo). ícones possuem uma relação de semelhança com o objeto 
que representam, sendo apto a evocar rapidamente a ideia do objeto representado pelo signo; índice formam uma conexão com a mensagem a que se referem, como é o caso de uma caveira indicando perigo eminente. Já os símbolos expressam mensagens aptas a representar ideais abstratas, como é o caso de logomarcas ou diagramas de fluxo de processos.

c) A relação do signo com o interpretante, ou como representação para seu interpretante. (rema, dicente e argumento). Um rema é um signo que é interpretado como representante de alguma qualidade que poderia se atribuir a algum objeto possivelmente existente; Já o dicente se caracteriza como um signo interpretado como portador de uma outra informação sobre um signo já existente; por outro lado o argumento é um signo percebido como um signo de lei, regra ou princípio (SANTAELLA, op cit).

\section{A SEMIÓTICA NO MAPEAMENTO DOS PROCESSOS CONTIDOS NO SISTEMA DE EXCELÊNCIA GERENCIAL.}

O Modelo de Excelência da Gestão está alicerçado sobre um conjunto de conceitos fundamentais descritos nos conceitos Fundamentais da Excelência da Gestão, que aborda o contexto social, tecnológico e econômico em que as organizações se encontram. (Fundação Nacional da Qualidade - FNQ, 2013).

Os Fundamentos da Excelência expressam conceitos reconhecidos internacionalmente e se traduzem em práticas ou fatores de desempenho encontrados em organizações líderes de classe mundial, que buscam constantemente se aperfeiçoar e se adaptar às mudanças globais. Os fundamentos que se baseiam os critérios de Excelência da FNQ são: (Fundação Nacional da Qualidade -FNQ, 2013). 1. Pensamento sistêmico; 2. Aprendizado organizacional; 3. Cultura de inovação; 4. Liderança e Constança de propósitos; 5. Orientação por processos e informações; 6 . Visão de futuro; 7 . Geração de valor; 8. 
Valorização das pessoas; 9. Conhecimento sobre o cliente e o mercado; 10. Desenvolvimento de parcerias.

No modelo, os Fundamentos da Excelência são expressos em características tangíveis e distribuídos em requisitos. Estes são agrupamentos cujo objetivo maior é reproduzir de forma lógica a condução de temas essenciais de um negócio e que são denominados de critérios e de itens. O Modelo de Excelência da Gestão é representado pelo diagrama baixo, o que permite ao administrador obter uma visão sistêmica da gestão organizacional. (Fundação Nacional da Qualidade - FNQ, 2013).

Figura 3.: Visão Sistêmica da Gestão Organizacional

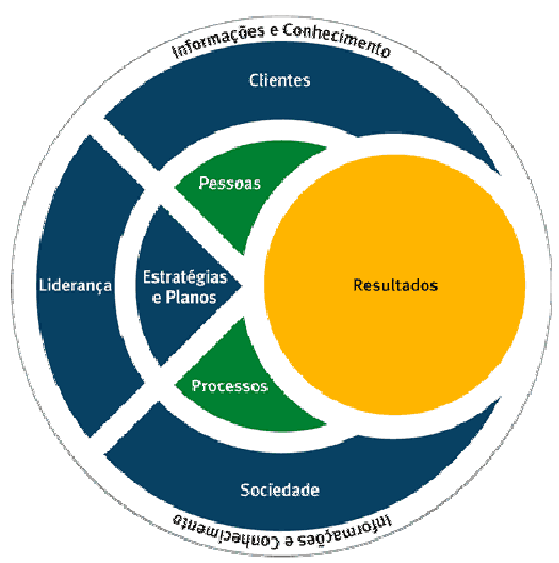

Fonte: Fundação Nacional Da Qualidade - FNQ, 2014

A figura representativa do Modelo de Excelência Gerencial, traz no seu bojo aspectos semióticos importantes para representar a intenção do modelo, na medida em que simboliza a organização, considerada como um sistema orgânico e adaptável ao ambiente externo e organiza os seus oito critérios de forma sistêmica, evidenciando o seu caráter interdependente e complementar, visando a geração de resultados. O modelo utiliza o conceito de aprendizado, de acordo com o ciclo do PDCL (Plan, Do, Check, Learn), ou seja, planejar, fazer, controlar e aprender. Planejar significa buscar identificar, entender e satisfazer as necessidades expectativas dos clientes e da sociedade. Neste caso, o papel do gestor é de extrema importância, tanto na 
análise do desempenho quanto na execução das ações. Eles determinam a posição competitiva e desdobram essa estratégia em planos de ação de curto, médio ou longo prazo, alocando recursos para assegurar a implementação das estratégias. $\mathrm{Na}$ etapa do fazer, o processo engloba pessoas e processos. As pessoas devem estar capacitadas e satisfeitas, atuando em um ambiente propício à consolidação da cultura da excelência, para que os processos sejam executados conforme o planejado. Controlar significa conferir, analisar, o que está sendo colocado em prática para garantir o que todo o ciclo se realize da melhor forma. Nesta etapa são medidos os resultados em relação a situação econômica, clientes e mercado, pessoas, sociedade, processos e fornecedores. E finalmente aprender, que se estabelecem em forma de informações e conhecimentos, para que haja execução das ações e a busca do aprendizado organizacional. Essas informações representam a inteligência da organização, viabilizando a análise do desempenho e a execução das ações necessárias. Todo o ciclo PDCL, ao ser executado, deverá conduzir a resultados, que devem ser analisados e entendidos, em função dos processos descritos que geram $\mathrm{g}$ informações e conhecimento para serem utilizados no processo de tomada de decisão.

Fica patente que a geração da informação e conhecimento permeia e envolve todo o processo de planejamento, execução, controle e aprendizagem, neste sentido o modo como se disponibiliza a informação é de extrema importância para se conseguir os produtos esperados de cada etapa deste ciclo.

A elaboração do relatório de gestão é uma das etapas mais significativas contempladas no Modelo de Excelência na Gestão da Fundação Nacional da Qualidade. O relatório deve descrever as práticas de gestão que representem os processos gerenciais desenvolvidos na organização.

A forma de comunicar as práticas de gestão é um dos grandes desafios do texto descritivos do relatório de gestão, neste sentido a 
Mac Amaral Cartaxo; Cláudio Gottschalg Duque

Aspectos da Arquitetura da Informação envolvidos no mapeamento de processos em Organizações Militares sob a perspectiva semiótica

multimodalidade oferece uma perspectiva significativa para proporcionar mecanismos intra discursivos dos quais resultem a constituição dos sentidos dos sistemas semióticos que compõem os textos.

A figura a seguir caracteriza um exemplo de descrição de uma prática de gestão um processo, por intermédio de um fluxograma que é uma forma de utilizar recursos semióticos para representar as atividades do processo de aquisição de material em uma organização militar.

Figura 4: Exemplo de Fluxograma que representativo de uma prática de gestão

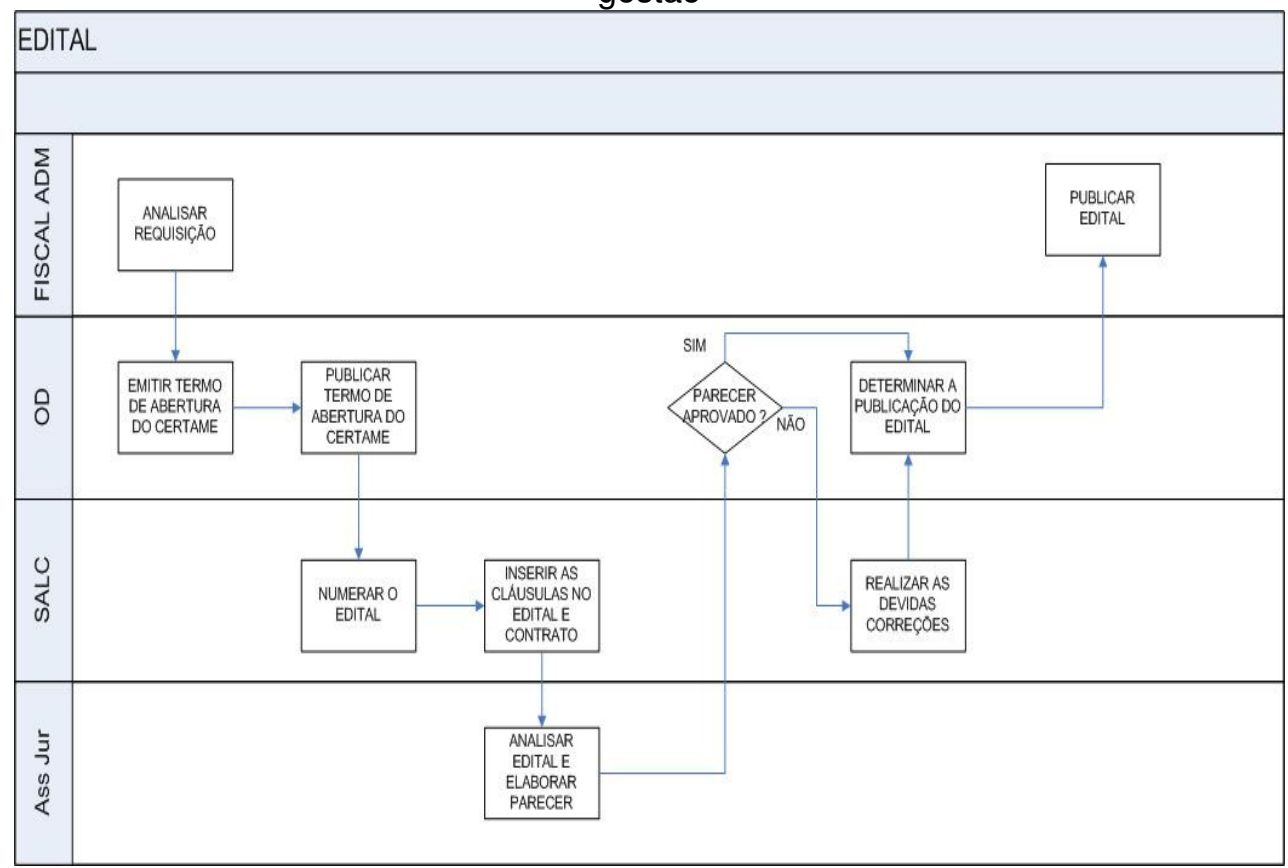

Fonte: Sistema de Excelência Gerencial do Exército Brasileiro - WEB 20151

Para representar e documentar as práticas de gestão o Exército desenvolveu uma ferramenta informatizada de gestão do Sistema de Excelência no Exército Brasileiro (SE-EB) que foi chamado Sistema de Excelência Gerencial do Exército Brasileiro ou simplesmente "SISPEG" que foi implementado numa versão para computador a partir de 2003, tendo evoluído a partir de 2007 para uma versão para plataforma WEB, onde com acesso via Internet, permite o gerenciamento dos Planos de

\footnotetext{
${ }^{1}$ https://www.sispegweb.ensino.eb.br/. Acesso em 18/05/2015
}

Inf. Inf., Londrina, v. 21, n. 1, p. 103 - 130, jan./abr. 2016. 
Gestão, Auto-Avaliação, Validação, Melhores Práticas de Gestão, Relatórios, Banco de Melhores Práticas, Cadastro da OM, Cadastro do Assessor de Gestão e Visão Sistêmica das OM. Contribui com o Sistema de Medição de Desempenho Organizacional com base no Balanced Scorecard (SMDO/BSC), alinhando os Indicadores de Desempenho Operacionais e Estratégicos das OM de nível Batalhão / Subunidade até os seus respectivos Comandos Militares de Área, sem contar as organizações de nível mais estratégico, como é o caso dos órgãos de direção geral, setorial e de assessoramento direto e imediato.

A figura seguinte sinaliza uma prática de gestão que era desenvolvida no âmbito do Exército e que apesar dos dados demonstrarem que este processo não se encontrava com resultados favoráveis foi a partir da sua mensuração e apresentação em termos gráficos no histograma contido no Sistema de Excelência Gerencial do Exército Brasileiro - versão WEB que se decidiu por descontinuar esta prática de gestão que não melhorava e estava longe do seu referencial comparativo em termos de padrão de qualidade aceitável.

Figura 5 - Exemplo de indicador que representa os resultados de uma prática de gestão

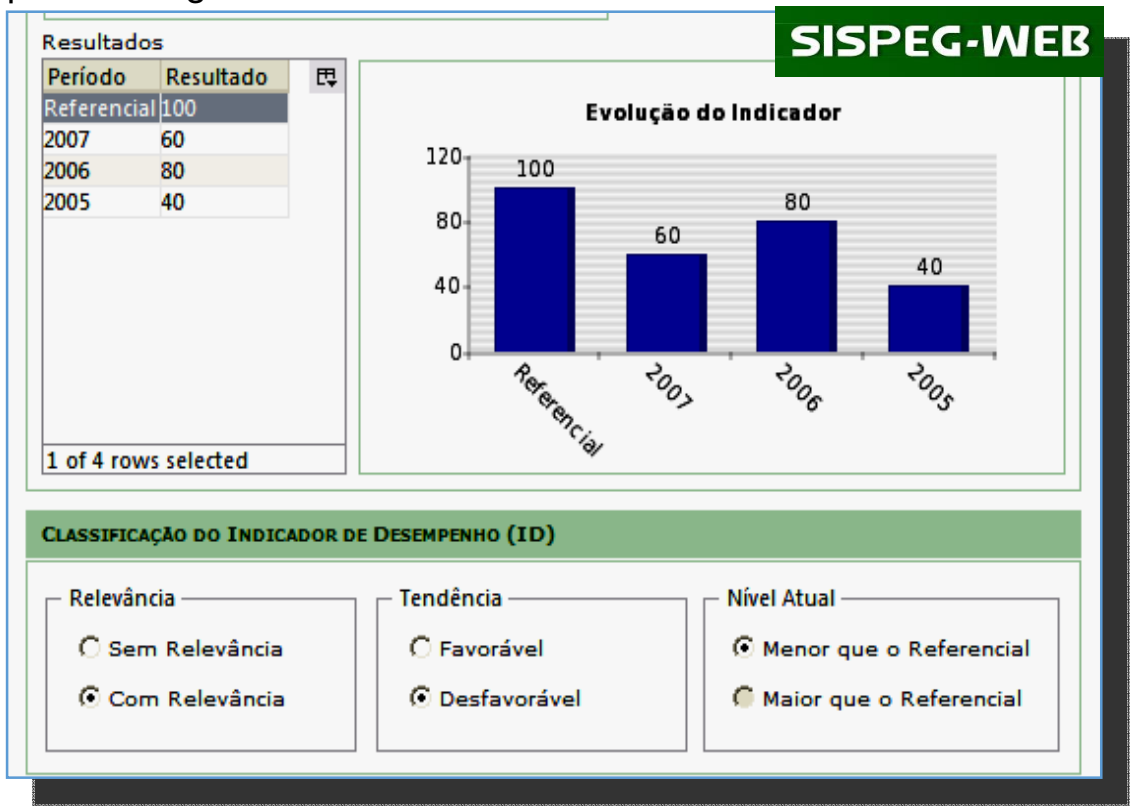

Fonte: Sistema de Excelência Gerencial do Exército Brasileiro - WEB 2015

Inf. Inf., Londrina, v. 21, n. 1, p. $103-130$, jan./abr. 2016. 
Analisando sob a perspectiva semiótica de Peirce as informações sobre processos contidos no Sistema de Excelência Gerencial do Exército Brasileiro em termos de primeiridade, secundidade e terceiridade a luz das respostas fornecidas pelos assessores de gestão, pôde ser elaborado o quadro-resumo a seguir:

Quadro 1: Semiótica dos processos registrados no Sistema de Excelência Gerencial do Exército Brasileiro - versão WEB

\begin{tabular}{|c|c|}
\hline $\begin{array}{l}\text { Perspectiva } \\
\text { de Peirce }\end{array}$ & ercepção sobre semiótica dos processos organizacionais. \\
\hline Primeiridade & $\begin{array}{l}\text { Os assessores descrevem que num primeiro momento as } \\
\text { organizações não reconheciam os fluxos dos processos e até uma } \\
\text { certa dificuldade em interpretar os signos atribuídos, ou seja como } \\
\text { qualisigno não era aceito num primeiro momento }\end{array}$ \\
\hline Secunidade & $\begin{array}{l}\text { Todos os assessores relataram que a descrição dos processos no } \\
\text { sistema ,bem como a forma como passam a ser apresentados os } \\
\text { indicadores se caracterizou como um grande avanço para a gestão } \\
\text { das organizações, na medida em que passam de maneira objetiva } \\
\text { informações sobre os processos que anteriormente não eram } \\
\text { percebidas, como é o caso da quantidade de pessoal alocado para } \\
\text { realização das atividades, tempo dispendido, e as entregas } \\
\text { efetivamente realizadas por cada processo, deste modo se verifica } \\
\text { a existência de um dissigno ou dicente, pois outras informações } \\
\text { foram trazidas à baila, além daquelas que se imaginava obter na } \\
\text { apresentação destes signos. }\end{array}$ \\
\hline Terceiridade & $\begin{array}{l}\text { Atualmente, após um intenso processo de capacitação, bem como } \\
\text { em função do perfil amigável da facilidade de acesso pela WEB a } \\
\text { disseminação dos diagramas e tabelas utilizados tornaram os } \\
\text { fluxos reconhecidos como símbolos e o signo possível de ser } \\
\text { aceito como um legisigno no âmbito da organização, tendo se } \\
\text { transformado, praticamente, num padrão para o planejamento e } \\
\text { monitoramento das ações gerenciais desenvolvidas. }\end{array}$ \\
\hline
\end{tabular}

Fonte: Elaboração própria.

A primeiridade se caracterizara pela exuberância visual para atrair a atenção responsável, seja em função da diagramação das informações, o que se consegue por meio de cores intensas dos indicadores representados como histogramas, ou das tabelas utilizadas para sintetizar os requisitos de cada um dos processos. A secundidade é percebida pois existe a correta interpretação dos elementos semióticos utilizados nos símbolos dos fluxogramas definidos no Modelo de Excelência Gerencial do Exército Brasileiro (MEG-EB). Os membros da organização militar demonstram o ingresso na terceiridade proposta por Peirce quando conseguem compreender, interpretar, e traduzir os 
signos presentes no fluxo, gráficos ou diagramas que descrevem os processos por reconhecerem seus elementos como legisignos.

\section{CONSIDERAÇÕES FINAIS}

Este artigo buscou analisar os aspectos da Arquitetura da Informação envolvidos no mapeamento de processos sob uma perspectiva semiótica, deste modo se verificou que a Arquitetura da Informação proporciona espaços informacionais para atender as necessidades de informação das pessoas e organizações, enquanto o mapeamento de processos está vinculado a descrição e estudo das atividades, insumos, fornecedores, produtos/serviços e clientes inerentes a uma prática de gestão, bem como os modos utilizados para subsidiar a compreensão das ações gerenciais e operacionais, além de seus resultados em um determinado contexto.

Considerando que o mapeamento de processos se utiliza de diversos aspectos semióticos para melhor representar, recuperar e disseminar as informações gerenciais de uma organização as, pode-se perceber que a Arquitetura da Informação e o mapeamento de processos com a utilização de aspectos semióticos atuam de forma interativa e complementar no sentido de proporcionar informações oportunas para os usuários.

Os resultados obtidos na pesquisa caracterizaram a arquitetura da informação como um importante instrumento para que as organizações militares em sua busca por regularidade $\mathrm{e}$ desenvolvimento obtenham a padronização dos seus processos, de modo que possam ser replicados e disseminados em vários locais. Neste sentido, o mapeamento de um processo se mostra imprescindível para garantir está regularidade e padronização de procedimentos.

Neste sentido a informação foi percebida como a matéria-prima básica, da qual dependem os processos de negócio do Exército. Assim, quanto mais importante for certa informação para as necessidades da 
organização, e quanto mais rápido for o acesso a ela, com maior eficácia as organizações poderão atingir os seus objetivos. Levy (1997) corrobora com esse pensamento, apontando que a informação e o conhecimento são as principais fontes de riqueza, e McGee e Prusak (1994) mencionam que, na Sociedade da Informação, o sucesso é determinado pelo saber, e não, somente pelo que se possui.

Como a descrição dos processos de negócio se encontra agora em um repositório (SISPEG-WEB) verificou-se que a existência de uma arquitetura da informação que possibilitou a modelagem de requisitos para o estabelecimento de um padrão para o planejamento e monitoramento das ações gerenciais desenvolvidas.

Sob o ponto de vista organizacional, há que se destacar também a definição de Brancheau e Wetherbe, os quais afirmam que Arquitetura da Informação consiste em um plano para modelagem dos requisitos informacionais de uma organização. Esse plano provê um modo de mapear as informações necessárias à organização, relativas aos processos do negócio e documentar seus inter-relacionamentos (BRANCHEAU E WETHERBE, 1986).

Deste modo, a arquitetura da informação subjacente ao SISPEG-WEB possibilitou que o processo de negócio mapeado descreve-se um conjunto de signos que apresentam as etapas, atividades, atores, contexto e condições inerentes ao andamento de um processo. Pode-se então entender que o processo de significação está na base do pensamento, quando refletimos sobre o mundo e seus eventos, e da troca de informações, na comunicação que torna ideias, afetos e comportamentos comuns.

A partir de uma análise semiótica baseada na abordagem triádica de Peirce pode-se inferir que houve uma melhora no processo transmissão da informação, pois os elementos semióticos contidos no Modelo de Excelência Gerencial foram representados e reconhecidos de modo a caracterizar uma evolução em termos de primeiridade, 
secundidade e terceiridade, ou seja, um relacionamento mais dinâmico e claro entre o signo, interpretante e seu objeto.

Percebe-se que a utilização da abordagem semiótica para entender como a arquitetura da informação pode contribuir sobremaneira para maximizar o modo como o mapeamento de um processo pode representar e organizar a informação, pois pensar na informação do ponto de vista semiótico pode enriquecer a nossa compreensão desse fenômeno e contribuir para o aprimoramento das ações desenvolvidas pelos profissionais que desenvolverá o levantamento das informações que devem estar contempladas no processo mapeado, de modo a facilitar a mediação entre usuário e informação. O ponto de vista semiótico pode contribuir para a expansão da noção de informação utilizada na arquitetura da informação.

\section{REFERÊNCIAS}

BACHA, M. L.; STREHLAU, V. I. Propaganda na TV não vende carros. A semiótica ajuda a entender por que. In: 29o ENANPAD, 2005, Brasília. Anais eletrônicos do XXIX ENANPAD. Brasília: ANPAD, 2005.

BAILEY, S. Information architecture: a brief introduction. The Information Architecture Institute, Beverly, Massachusetts, Mar. 12, 2003. Disponível em: <http://iainstitute.org/tools/download/BaileyIAlntro.pdf>. Acesso em: 15 jul. 2013.

\section{BALDRIGE NATIONAL QUALITY PROGRAM. Criteria for}

Performance Excellence. Edition 2006. Gaithersburg, MD: National Institute of Standards and Technology (NIST), 2006.

BELTON, K. A Design Foundation for Information Architecture. In: MORROGH, E. Information Architecture: An Emerging 21st Century Profession. New Jersey: Prentice Hall, 2003, cap. 22, p. 143-153.

BENNER, M.J., TUSHMAN, M.L.Exploitation, Exploration, and Process Management: The Productivity Dilemma Revisited', Academy of Management Review 28(2), 2003

BRANCHEAU, J. C.; WETHERBE, J. C. Information Architectures: Methods and Pratice. Information Processing \& Management, v. 22, n. 6, p. 453-463, May 1986. 
CERVO, A. L.; BERVIAN, P. A. Metodologia Científica: para uso dos estudantes universitários. São Paulo: McGraw-Hill do Brasil, 1983.

$\mathrm{CHOO}, \mathrm{C}$. W. A organização do conhecimento: como as organizações usam a informação para criar significado, construir conhecimento e tomar decisões. São Paulo: SENAC, 2003.

CROSBY, P. B. Quality is Free: The Art of Making Quality Certain. New York: McGraw- Hill, 1979.

CONSULTA DE INDICADORES DE GESTÃO: Ministério da Defesa, 2015. Disponível em: < https://www.sispegweb.ensino.eb.br/ > . Acesso em: 18 maio 2015.

DAVENPORT, T. H. Ecologia da informação: por que só a tecnologia não basta para o sucesso na era da informação. São Paulo: Futura, 1998.

DEMING, W. E. Out of the Crisis. Cambridge, MA: Massachusetts Institute of Technology, Center for Advanced Engineering Study, 1986.

ECO, H. Teoria geral da semiótica. São Paulo: Editora Perspectiva, 1980.

FEIGENBAUM, A. V. Total Quality Control. Harvard Business Review, v. 34, n. 6, p. 93- 101, 1956.

FUNDAÇÃO NACIONAL DA QUALIDADE (FNQ). Critérios de Excelência. Edição 2012. São Paulo, 2013.

GARRETT, J. Um vocabulário visual para Al e Design de Interação. Afifa, 2004. Disponível em: http://aifia.org/pt/translations/000332.html. Acesso em: 24 Maio 2014.

GIL, A. C. Como elaborar projetos de pesquisa. 4. ed. São Paulo: Atlas, 2002.

HAMMER, M.; STANTON, S. How process enterprises really work. Harvard Business Review, v.77, n.6, p.108-118, nov./dec., 1999.

HUBER, G. P. Organization Information System: The contributing processes and the literature. Organization Science, Mangement Science, 1991.

JURAN, J. M. Managerial Breakthrough. New York: McGraw-Hill, 1964.

LIMA-MARQUES, M. Outline of a theoretical framework of

Architecture of Information: a School of Brasilia proposal. In: BEZIAU, J.-Y.; CONIGLIO, M. E. (Eds.) 2011. 
LEVY, Michael. Computer-assisted language learning: context and conceptualization. New York: Oxford University Press, 1997.

MACEDO, F.L.O. Arquitetura da informação: aspectos epistemológicos, científicos e práticos. 186 f. Dissertação (Mestrado em Ciência da Informação) - Faculdade de Ciência da Informação, Universidade de Brasília: Brasília, 2005.

MARCH, J. G. Exploration and Exploitation in Organizational Learning. Organization Science, v. 2, n. 1, p. 70-87, 1991.

McGEE, J. V.; PRUSAK, L. Gerenciamento estratégico da informação. 10. ed. Rio de Janeiro: Campus, 1994

NIELSEN, J.; TAHIR, M. Home Page: Usabilidade. Rio de Janeiro: Campus, 2002.

PEIRCE, C. S. Collected papers. Cambridge: Harvard University Press., 1935

ROSENFELD, L.; MORVILLE, P.Information architecture for the world wide web.2. ed. Sebastopol: O'Really, 2002.

RUMMLER, Geary A., BRACHE Alan P.; Melhores Desempenhos das Empresas - Uma abordagem Prática para Transformar as Organizações através da reengenharia, Editora Makron Books, SP, 1994.

SANTAELLA, Lúcia. O que é Semiótica. São Paulo, Brasiliense, 2003. Matrizes da linguagem e pensamento: sonora, visual, verbal: aplicações na hipermídia. São Paulo: lluminuras e FAPESP, 2005.

YIN, R. Estudo de Casos: planejamento e Métodos. Porto Alegre, Bookman, 2005

TOUB, S. Evaluating information architecture: a practical guide to assessing web site organization. 2000. Disponível em: <http://argusacia.com/white_papers/evaluating_ia.pdf>. Acesso em: 25 jul. 2012.

WODTKE, C. Information Architecture: Blueprints for the web. Indianapolis: New Riders, 2003.

\section{Title}

Aspects of Information Architecture involved in process mapping in Military Organizations under the semiotic perspective 


\begin{abstract}
Introduction: The description of the processes to represent the activities in an organization has important call semiotic, It is the flowcharts of uses, management reports and the various forms of representation of the strategies used. The subsequent interpretation of the organization's employees involved in learning tasks and the symbols used to translate the meanings of management practices is essential role for the organization.

Objective: The objective of this study was to identify evidence of conceptual and empirical, on aspects of information architecture involved in the mapping process carried out in military organizations under the semiotic perspective.

Methodology: The research is characterized as qualitative, case study and the data collection technique was the semi-structured interview, applied to management advisors.

Results: The main results indicate that management practices described with the use of pictorial symbols and different layouts have greater impact to explain the relevance of management practices and indicators.

Conclusion: With regard to the semiotic appeal, it was found that the impact of a management report is significant due to the use of signs and layout that stimulate further reading by simplifying complex concepts in tables, diagrams summarizing lengthy descriptions.
\end{abstract}

Keywords: Information Architecture. Process Mapping. Managerial Excellence. Military organizations. Semiotics.

\title{
Titulo
}

Proceso de comunicación en el ambiente interno de una industria: comprensiones a partir del análisis de contenido

\section{Resumen}

Introducción: La descripción de los procesos para representar las actividades de una organización tiene llamada importante semiótica, son los diagramas de flujo de aplicaciones, informes de gestión y las distintas formas de representación de las estrategias utilizadas. La interpretación posterior de los empleados de la organización que participan en las tareas de aprendizaje y los símbolos utilizados en la conversión de los significados de las prácticas de gestión es el papel esencial de la organización.

Objetivo: El objetivo de este estudio fue identificar la evidencia de conceptual y empírico, sobre aspectos de la arquitectura de la información que intervienen en el proceso de mapeo llevado a cabo en las organizaciones militares bajo la perspectiva semiótica.

Metodología: La investigación se caracteriza por ser, estudio de caso cualitativo y la técnica de recolección de datos fue la entrevista semiestructurada, aplicada a los asesores de gestión.

Resultados: Los principales resultados indican que las prácticas de gestión descritas con el uso de símbolos pictóricos y diferentes diseños tienen un mayor impacto para explicar la relevancia de las prácticas e indicadores de gestión. 
Mac Amaral Cartaxo; Cláudio Gottschalg Duque

Aspectos da Arquitetura da Informação envolvidos no mapeamento de processos em Organizações Militares sob a perspectiva semiótica

Conclusión: Con respecto a la apelación semiótica, se encontró que el impacto de un informe de gestión es significativo debido a la utilización de los signos y de diseño que estimulan la lectura aún más mediante la simplificación de conceptos complejos en tablas, diagramas que resumen largas descripciones.

Palabras clave: Arquitectura de la Información. Mapeo de Procesos. Excelencia en la gestión. Las organizaciones militares. La semiótica.

Recebido: 23.06.2015

Aceito: 09.04.2016 